NBER WORKING PAPER SERIES

WHAT IS THE PROBABILITY YOUR VOTE WILL MAKE A DIFFERENCE?

Andrew Gelman

Nate Silver

Aaron Edlin

Working Paper 15220

http://www.nber.org/papers/w15220

\author{
NATIONAL BUREAU OF ECONOMIC RESEARCH \\ 1050 Massachusetts Avenue \\ Cambridge, MA 02138
}

August 2009

We thank an anonymous reviewer for helpful comments and the National Science Foundation for financial support. The views expressed herein are those of the author(s) and do not necessarily reflect the views of the National Bureau of Economic Research.

NBER working papers are circulated for discussion and comment purposes. They have not been peerreviewed or been subject to the review by the NBER Board of Directors that accompanies official NBER publications.

(C) 2009 by Andrew Gelman, Nate Silver, and Aaron Edlin. All rights reserved. Short sections of text, not to exceed two paragraphs, may be quoted without explicit permission provided that full credit, including $\odot$ notice, is given to the source. 
What is the probability your vote will make a difference?

Andrew Gelman, Nate Silver, and Aaron Edlin

NBER Working Paper No. 15220

August 2009

JEL No. H0,K0

\section{$\underline{\text { ABSTRACT }}$}

s

One of the motivations for voting is that one vote can make a difference. In a presidential election, the probability that your vote is decisive is equal to the probability that your state is necessary for an electoral college win, times the probability the vote in your state is tied in that event. We computed these probabilities a week before the 2008 presidential election, using state-by-state election forecasts based on the latest polls. The states where a single vote was most likely to matter are New Mexico, Virginia, New Hampshire, and Colorado, where your vote had an approximate 1 in 10 million chance of determining the national election outcome. On average, a voter in America had a 1 in 60 million chance of being decisive in the presidential election.

Andrew Gelman

Department of Statistics

and Department of Political Science

Columbia University

New York, NY 10027

gelman@stat.columbia.edu

Nate Silver

Baseball Prospectus

Chicago IL

538dotcom@gmail.com
Aaron Edlin

The Richard W. Jennings '39 Endowed Chair

University of California, Berkeley

Department of Economics and School of Law

Berkeley, CA 94720-7200

and NBER

edlin@econ.berkeley.edu 


\title{
What is the probability your vote will make a difference? ${ }^{1}$
}

\author{
Andrew Gelman ${ }^{2}$, Nate Silver ${ }^{3}$, and Aaron Edlin ${ }^{4}$
}

25 Mar 2009

\begin{abstract}
One of the motivations for voting is that one vote can make a difference. In a presidential election, the probability that your vote is decisive is equal to the probability that your state is necessary for an electoral college win, times the probability the vote in your state is tied in that event. We computed these probabilities a week before the 2008 presidential election, using state-by-state election forecasts based on the latest polls. The states where a single vote was most likely to matter are New Mexico, Virginia, New Hampshire, and Colorado, where your vote had an approximate 1 in 10 million chance of determining the national election outcome. On average, a voter in America had a 1 in 60 million chance of being decisive in the presidential election.
\end{abstract}

\section{Introduction}

What is the probability that one vote will make a difference? This is of interest in the utility theory of voting and also for campaign strategists who must assess the costs and benefits of attempting to persuade or turn out voters in particular states. ${ }^{5}$ In a presidential election, the probability that your vote is decisive is equal to the probability that your state is necessary for an electoral college win, times the probability the vote in your state is tied, conditional on your state being necessary.

Broadly speaking, there are three ways of estimating the probability of a decisive vote. The first approach, and the oldest in the literature, ${ }^{6}$ is to set up a theoretical model for the joint distribution of the popular vote margin in the separate jurisdictions (in this case, the 50 states plus the District

\footnotetext{
${ }^{1}$ To appear in Economic Inquiry. We thank an anonymous reviewer for helpful comments and the National Science Foundation for financial support.

${ }^{2}$ Department of Statistics and Department of Political Science, Columbia University, gelman@stat.columbia.edu, http://www.stat.columbia.edu/ gelman

3 Baseball Prospectus, http://fivethirtyeight.com

${ }^{4}$ Richard Jenning Professor of Law and Professor of Economics, University of California, Berkeley, edlin@econ.berkeley.edu

${ }^{5}$ There is a large literature on utility models for voting; see, for example, Ferejohn and Fiorina (1974) and, for our own view, Edlin, Gelman, and Kaplan (2007). See Stromberg (2008) for a recent analysis of the relation between electoral strategy and the probability of a decisive vote.

${ }^{6}$ Examples include Good and Mayer (1975) and Chamberlain and Rothchild (1981); see Gelman, Katz , and Bafumi (2004) for a review of such methods and their relation to computing the empirical probability of decisiveness.
} 
of Columbia) and then analytically compute the probability of each state being nationally decisive and locally tied. Such models offer important insights but are not directly useful for presidential elections, given that our interest is in the particularities of individual states in 2008 rather than on general properties of an electoral system.

The second approach is purely empirical, an estimate of the form $y / n$, where $n$ is the number of elections in some large historical sample and y is the number that were tied. Elections are very rarely tied, so one can instead use an estimate such as $y /(2000 n)$, where y is now the number of elections decided by less than 1000 votes. Such an empirical analysis can be embedded into a regression of vote differential on election-level predictors. Mulligan and Hunter (2003) use such a model for estimating the average probability of a decisive vote in legislative elections, and Gelman, Katz, and Bafumi (2004) use the distribution of aggregate vote margins to study the dependence of the probability of a tie on the number of voters. ${ }^{7}$ Unfortunately, the complex structure and the small number of presidential elections rule out a purely empirical approach in this case.

The third method, which we use here, is to set up a forecasting model for the current election. The uncertainties for the 50 statewide elections in such a model should be correlated —or, equivalently, the model should have a national error term, and possibly regional error terms, in addition to any independent state errors. Given a forecast that is a joint probability distribution, one can calculate the probability of decisive vote using simulation or, in a setting such as a national election in which the probability of a tied election is tiny, one can use a mix of simulation and analytic calculations as was done by Gelman, King, and Boscardin (1998). ${ }^{8}$

\section{Method}

We use a state-by-state election forecast computed on 24 October 2008 using based on the latest opinion polls (Silver, 2008). Earlier in the campaign, polls are not particularly informative, and it is better to use regression-based forecasts, at least to account for possible national swings (see Lock and Gelman, 2008 and, for further discussion, Wlezien and Erikson, 2004, and the

\footnotetext{
${ }^{7}$ An objection sometimes arises about this sort of calculation that one vote never makes a difference, because if the election were decided by one vote, there would be a recount anyway. Gelman, Katz, and Bafumi (2004, p. 674) discuss why this argument is wrong, even for real elections with disputed votes, recounts, and so forth. This can be shown by setting up a more elaborate model that allows for a gray area in vote counting and then demonstrating that the simpler model of decisive votes is a reasonable approximation.

${ }^{8}$ Another approach, which we do not consider here, is to derive an implicit probability distribution for vote outcomes using the prices on election betting markets. This method might seem appealing at first but it falls apart in practice, at least based on the current state of the betting markets. For example, www.intrade.com assigned McCain a ridiculously high 3\% chance of winning the District of Columbia. Prediction markets do have a role as information aggregators, especially for primary elections, where polls are highly unstable and models based on fundamentals do not do particularly well. But for the general election, incorporating information from prediction markets seems hardly worth the effort. Certainly we can't take the market's implied probabilities at face values.
} 
references therein). By late October, however, polls are close to the actual election outcome and so it is reasonable to construct a forecast distribution using poll aggregation. ${ }^{9}$

The result of our forecasts is a 10,000 x 51 matrix representing 10,000 computer simulations of the election, with each simulation including the vote margin for Obama (for example, a margin of -.208 in Alabama corresponds to Obama and McCain receiving 60.4\% and 39.6\%, respectively, of the two-party vote in the state). We convert this percentage to a numerical vote margin by multiplying by the voter turnout in the state (which we estimate by taking the twoparty turnout from 2004 and adding 4\% corresponding to population increase and another 4\% to account for an anticipated increase in turnout this year). ${ }^{10}$

As we have discussed above, the simulations for the states are correlated: the joint probability distribution of the 51 election outcomes includes uncertainty about the national swing as well as state-by-state fluctuations.

We use the forecasts to estimate the probability of a decisive vote in two steps. For each state:

1. Let $\mathrm{E}$ be the number of electoral votes in your state. We estimate the probability that these are necessary for an electoral college win by computing the proportion of the 10,000 simulations for which the electoral vote margin based on all the other states is less than E, plus $1 / 2$ the proportion of simulations for which the margin based on all other states equals E. (This last part assumes implicitly that we have no idea who would win in the event of an electoral vote tie. $)^{11}$

2. We estimate the probability that your vote is decisive, if your state's electoral votes are necessary, by working with the subset of the 10,000 simulations for which the electoral vote margin based on all the other states is less than or equal to E. We compute the mean $\mathrm{M}$ and standard deviation $\mathrm{S}$ of the vote margin among that subset of simulations and then

\footnotetext{
${ }^{9}$ Based on the economy and other factors, political scientists forecasted that the Democrats will receive $51.8 \%$ of the two-party vote (Hibbs, 2008) or maybe 52.2\% (Erikson and Wlezien, 2008). Such forecasts have standard errors large enough that the aforementioned researchers gave McCain a roughly 30\% chance of winning, given the information available as of June or August. Were we doing our analysis using pre-October polls, we would construct our probability distribution for the election outcome using a weighted average of recent polls and modelbased forecasts. (See also Campbell, 2008, for further information on recent forecasting models.) After the election, we compared state-by-state forecasts to actual election outcomes and found a very close match , with a difference of less than 1 percentage point in 22 states and a difference of less than 3 percentage points in 39 of the 50 states (Gelman and Sides, 2009).

${ }^{10}$ More sophisticated turnout models are possible, for example using recent polls on likely voting. But such adjustments would make only tiny changes to the probability of tie elections. All that is really important here is that we put in a reasonable guess at the total number of votes in each state. In retrospect, there were some differences from 2004 to 2008; for example, Indiana saw an increase in turnout of nearly five percentage points, while Ohio’s rate of voter turnout decreased slightly (McDonald, 2009).

${ }^{11}$ We ignored the splitting of Nebraska's and Maine's electoral votes, which retrospectively turned out to be a mistake in 2008, when Obama won an electoral vote from one of Nebraska's districts.
} 
compute the probability of an exact tie as the density at 0 of the Student-t distribution with 4 degrees of freedom, mean $\mathrm{M}$, and scale $\mathrm{S}^{12}$

The product of two probabilities above gives the probability of a decisive vote in the state.

Figure 1 maps the states based on their probability of a vote being decisive: your vote was, prospectively, most likely to matter in New Mexico, New Hampshire, Virginia, and Colorado, where a single vote had an approximate 1 in 10 million chance of determining the national election outcome.

Figure 2a plots these estimated probabilities as a function of the number of electoral votes in the state. A single vote was more likely to be decisive in smaller states, but the pattern is far from deterministic. Figure 2a shows how the probability of decisive vote (plotted this time on the logarithmic scale) depends on the anticipated closeness of the election. Your vote is much more likely to make a difference if you live in a state that is near the national median in partisanship.

Finally, in Figure 3 we decompose the two factors that determine the individual voter's chance of making a difference: the probability that your state will be needed for an electoral college win, and the probability that your stat is tied in that event. Larger states are more likely to be crucial in the electoral vote but less likely to be tied: for example, we estimate there is a $18 \%$ chance that the electoral vote margin will be less than 55 (so that California's 55 electoral votes will be crucial), but only a 1 in 100 million chance that California's immense popular vote will be tied if that happens. At the other extreme, we estimate a less than $1 \%$ chance that the electoral college will be so close that New Hampshire's 5 electoral votes will be necessary-but, if they are, the probability is a relatively high 1 in 70,000 of a tie vote in the state.

In summary, we estimate the probability of a single vote being decisive as, at most, about 1 in 10 million in a few states near the national median. Averaging these probabilities over all the states and weighting by turnout yields a 1 in 60 million chance that a randomly-selected voter would be decisive.

\section{Discussion}

A probability of 1 in 10 million is tiny but, as discussed by Edlin, Gelman, and Kaplan (2007), can provide a rational reason for voting; in this perspective, a vote is like a lottery ticket with a 1 in 10 million chance of winning, but the payoff is the chance to change national policy and improve (one hopes) the lives of hundreds of millions, compared to the alternative if the other

\footnotetext{
${ }^{12}$ The t distribution with 4 degrees of freedom is commonly used as a robust alternative to the normal (Lange, Little, and Taylor, 1989); we use it here to allow for the possibility of unanticipated shocks. Using the $t$ instead of the normal has little effect on the probability of a decisive vote in close states, but it moderates the results in states farther from the national median , for example changing the estimated probability of decisiveness in the District of Columbia from $5 \mathrm{e}-85$ to $2 \mathrm{e}-12$, in Utah from $9 \mathrm{e}-16$ to $2 \mathrm{e}-10$, but changing the estimate in Ohio only from 3.4e-8 to 3.1e-8.
} 
candidate were to win. ${ }^{13}$ Different voters have different opinions about which candidate is desirable, but many can feel that their preference is not only better for them personally but for millions of others. (On the other hand, for voters in states such as New York, California, and Texas where the probability of a decisive vote is closer to 1 in a billion, any reasons for voting must go beyond the any instrumental rationality.)

We can also consider the incentives for campaigns and voter organizers. We estimate that turning out 1000 additional voters for your side (or persuading 500 people to change their vote) in New Mexico would have a 1.3\% chance of flipping the state in the event (with probability $1.2 \%$ ) that its electoral votes are decisive, which combine to a 1 in 6000 chance of swinging the national election. The same effect could be attained at the national level by persuading 10,000 random supporters to vote or by persuading 5,000 random supporters of the other side to switch.

From a mathematical perspective it is unsurprising that the states near the national median are those where a vote is most likely to make a difference, and this is consistent with campaigns' focus on a few key swing states such as New Mexico, Virginia, New Hampshire, and Colorado. In 2008, Ohio, Florida, and Pennsylvania were in the second tier of priority.

\footnotetext{
${ }^{13}$ Hansen, Palfrey, and Rosenthal (1987) discuss the cost of voting, and Edlin, Gelman, and Kaplan (2008) estimate the dollar-equivalent benefits, considering voting as equivalent to a charitable contribution. Fowler (2006) gives experimental evidence relating altruism to voter turnout.
} 


\section{References}

Campbell, J. E. (2008). Forecasting the 2008 national elections. PS: Political Science and Politics 41, 679-681.

Chamberlain, G., and Rothchild, M. (1981). A note on the probability of casting a decisive vote. Journal of Economic Theory 25, 152-162.

Edlin, A., Gelman, A., and Kaplan, N. (2007). Voting as a rational choice: why and how people voter to improve the well-being of others. Rationality and Society 19, 293-314.

Erikson, R. S., and Wlezien, C. (2008). Leading economic indicators, the polls, and the presidential vote. PS: Political Science and Politics 41, 703-707.

Fowler, J. H. (2006). Altruism and turnout. Journal of Politics 68, 674-683.

Gelman, A., King, G., and Boscardin, W. J. (1998). Estimating the probability of events that have never occurred: when is your vote decisive? Journal of the American Statistical Association 93, 1-9.

Gelman, A., Katz, J. N., and Bafumi, J. (2004). Standard voting power indexes don't work: an empirical analysis. British Journal of Political Science 34, 657-674.

Gelman, A., and Sides, J. (2009). Election 2008: What really happened? And what does it mean? Technical report, Department of Statistics, Columbia University.

Good, I. J., and Mayer, L. S. (1975). Estimating the efficacy of a vote. Behavioral Science 20, 25-33.

Hansen, S., Palfrey, T. R., and Rosenthal, H. (1987). The Downsian model of electoral participation: formal theory and empirical analysis of the constituency size effect. Public Choice 52, 15-33.

Hibbs, D. A. (2008). Implications of the "bread and peace” model for the 2008 US presidential election. Public Choice 137, 1-10.

Lange, K. L, Little, R. J. A., and Taylor, J. M. G. (1989). Robust statistical modelling using the t-distribution. Journal of the American Statistical Association 84, 881-896.

Lock, K., and Gelman, A. (2008). Bayesian combination of state polls and election forecasts. Technical report, Department of Statistics, Columbia University.

McDonald, M. (2009). United States elections project. http://elections.gmu.edu/ 
Mulligan, C. B., and Hunter, C. G. (2003). The empirical frequency of a pivotal vote. Public Choice 116, 31-54.

Silver, N. (2008). Frequently asked questions.

http://www.fivethirtyeight.com/2008/03/frequently-asked-questions-last-revised.html

Stromberg, D. (2008). How the electoral college influences campaigns and policy: the probability of being Florida. American Economic Review 98, 769-807.

Wlezien, C., and Erikson, R. S. (2004). The fundamentals, the polls, and the presidential vote. PS: Political Science and Politics 37, 747-751. 


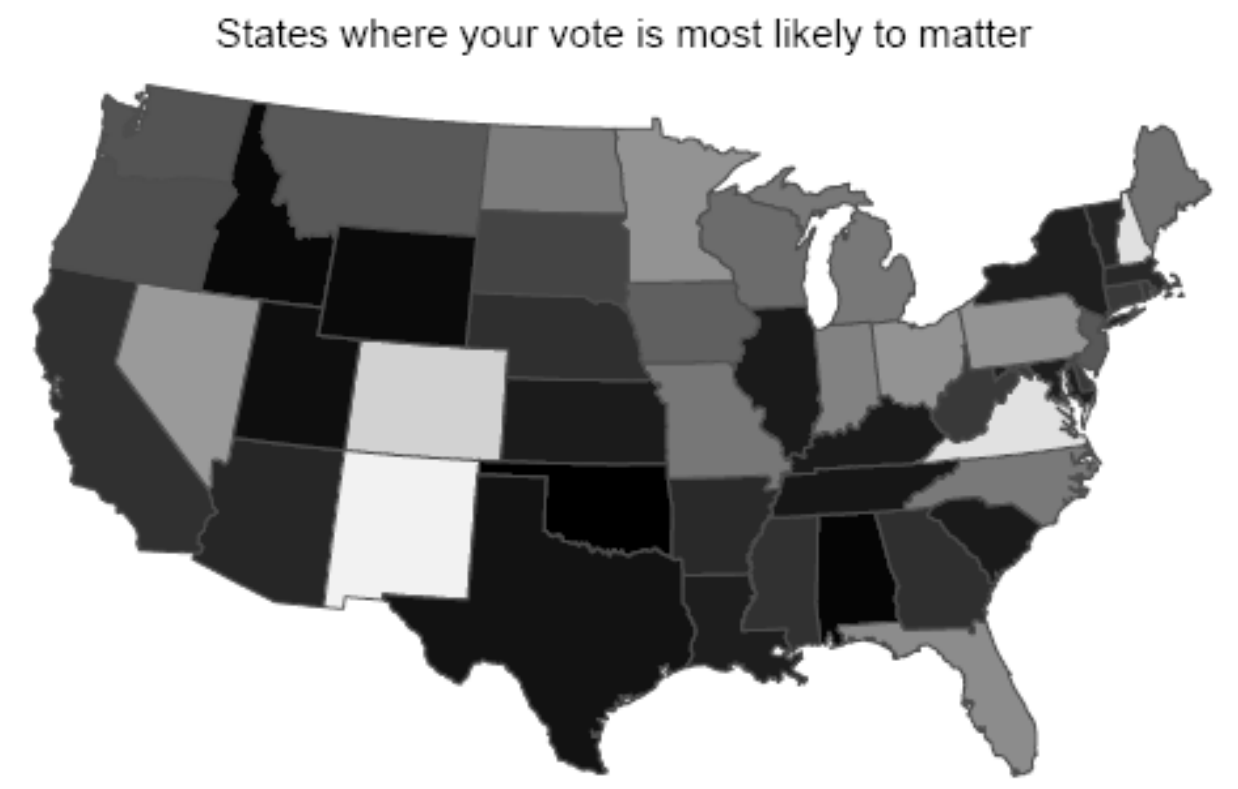

Figure 1. States with lighter colors are those where a single vote was more likely to be decisive. A single vote (or, for that matter, a swing of 100 or 1000 votes) was most likely to matter in New Mexico, New Hampshire, Virginia, and Colorado, where your vote had an approximate 1 in 10 million chance of determining the national election outcome. Alaska, Hawaii, and the District of Columbia are not shown on the map, but the estimated probability of a single vote being decisive was nearly zero in those locations. 
Probability of a decisive vote within each state

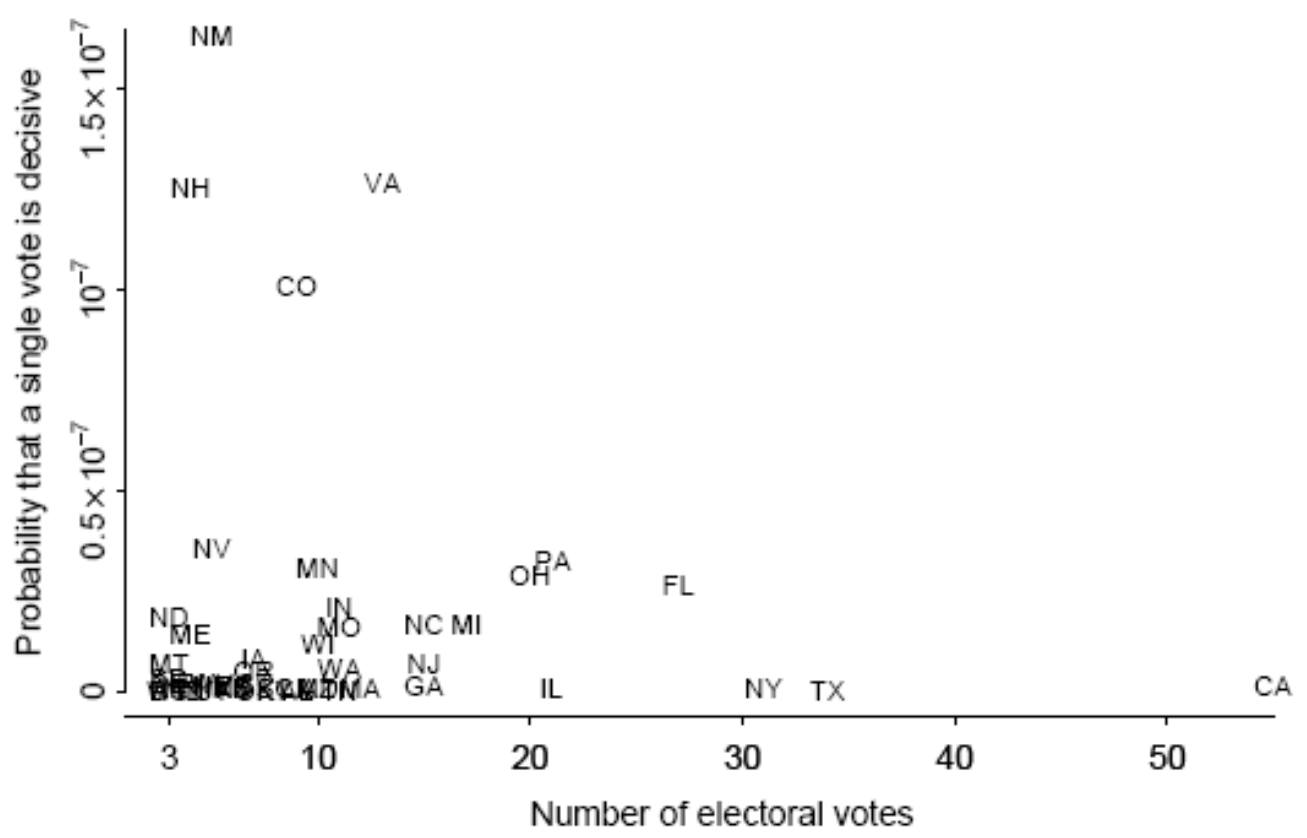

Probability of a decisive vote (logarithmic scale)

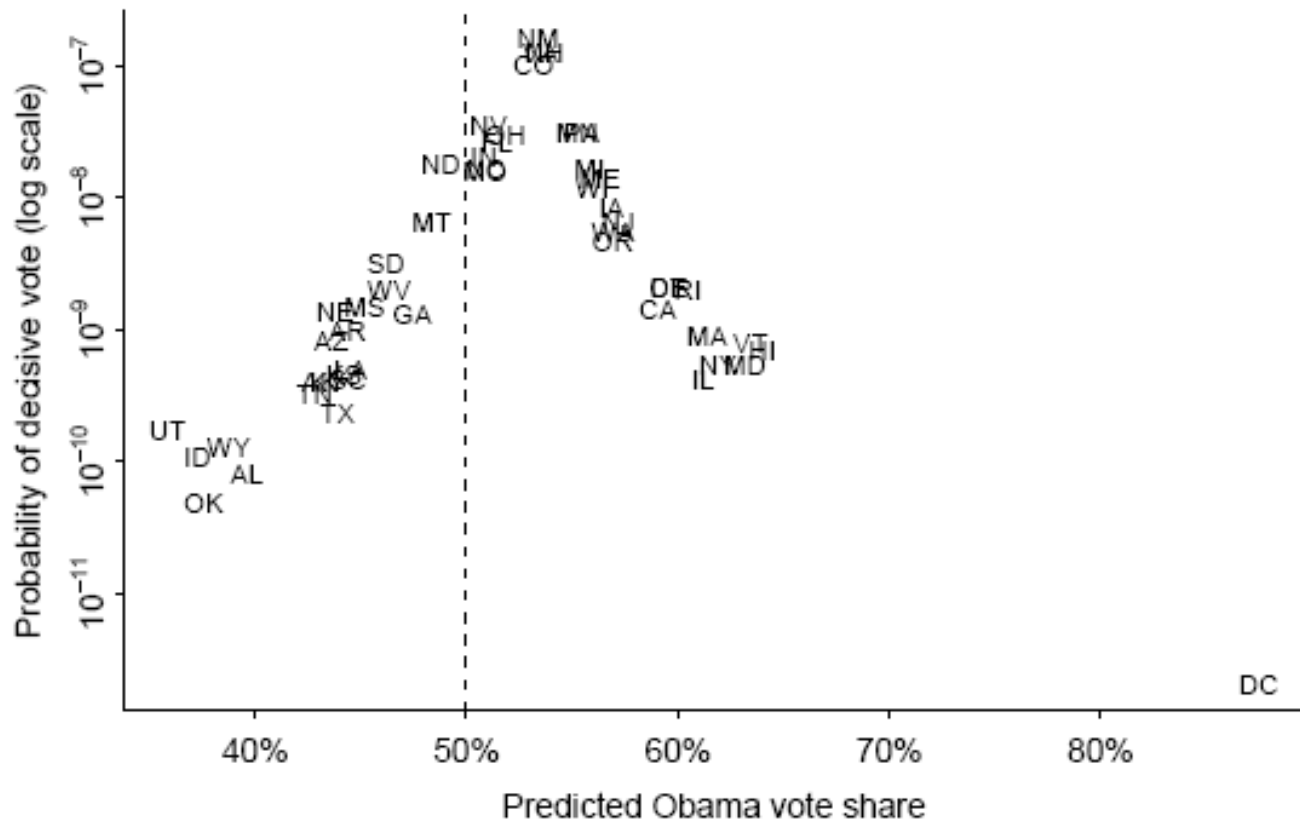

Figure 2. Probability of a decisive vote plotted vs. the number of electoral votes and, on the logarithmic scale, vs. Obama's predicted vote in each state. The probability that your vote matters is highest in a set of small and midsize states that are near the national median politically. 


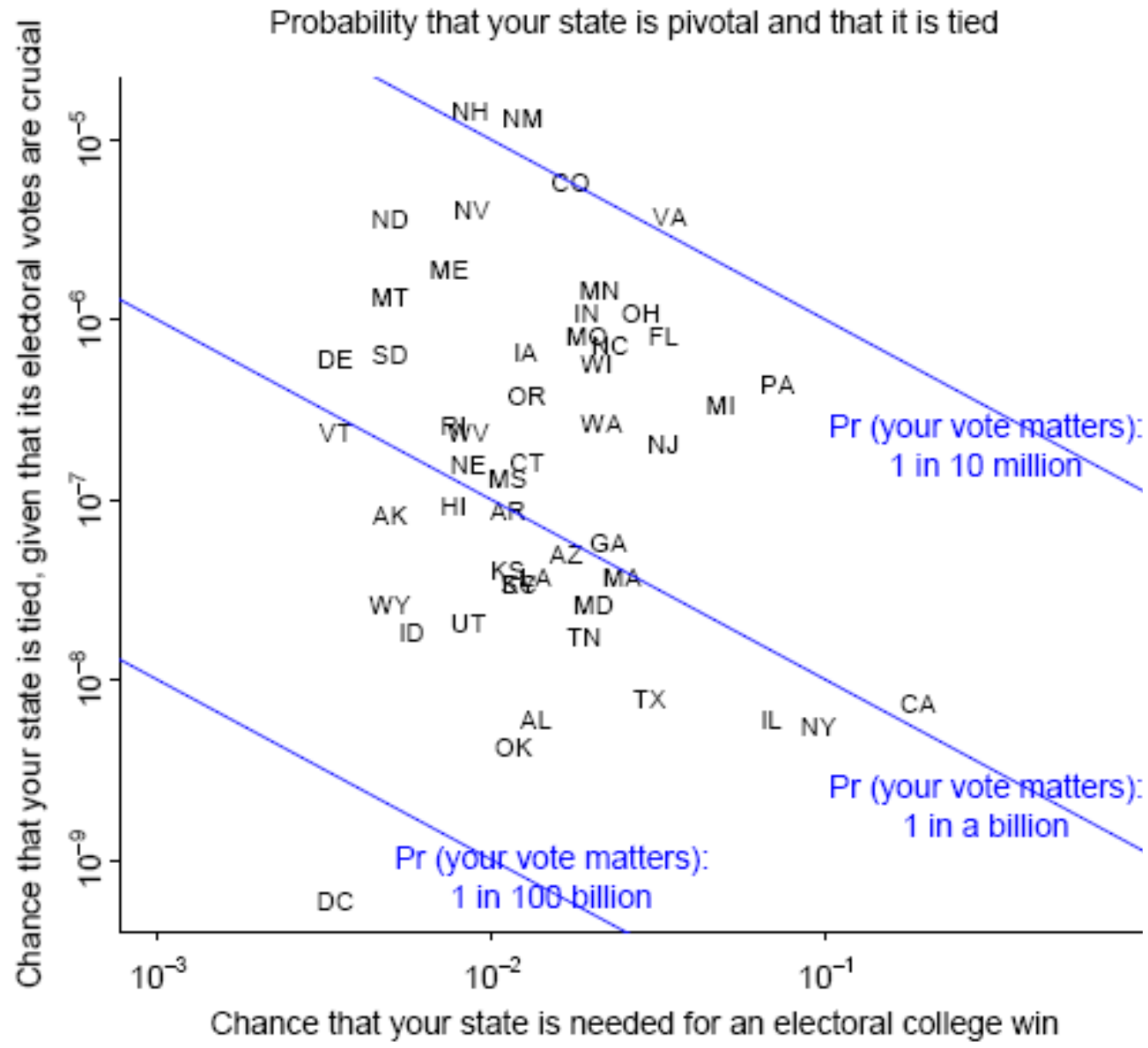

Figure 3. Probability that your vote in any particular state is decisive, factored into its two component parts: the probability of your state's electoral votes being necessary, and the probability of your state being tied, given that its electoral votes are necessary. The two probabilities multiply to give the chance that a single vote is pivotal. The blue lines show different levels of this probability, which is at most about 1 in 10 million. However, as discussed by Edlin, Gelman, and Kaplan (2007), it can be rational to vote even when your chance of being decisive is this low. 